\title{
BLURRING POSHUMAN IDENTITIES: THE NEW VERSION OF HUMANITY OFFERED BY BICENTENNIAL MAN (1999) ${ }^{1}$
}

\author{
SONIA BAELO ALLUÉ \\ Universidad de Zaragoza
}

\begin{abstract}
The aim of this paper is to analyse the 1999 film version of Isaac Asimov's "The Bicentennial Man" (1976), a film that reflects the changing status of the dichotomy human/non-human in our culture. The idea of blurring the human body boundaries has become one of the most repeated and successful subject matters of the science-fiction genre, a subject especially attractive in a time that some critics have defined as "post-human". Starting from Norbert Wiener theories we will see different approaches to the idea of the cyborg and the "post-human", which will help us to understand the changing relationship between machine, robot and cyborg in Bicentennial Man (1999). We will analyse in which ways the film answers the question: what does it mean to be human in a posthuman world?
\end{abstract}

\section{RESUMEN}

El propósito de este artículo es analizar la versión cinematográfica de 1999 de la historia corta “The Bicentennial Man"(1976) escrita por Isaac Asimov. Se trata de una película que refleja la cambiante posición de la dicotomía humano/no humano en nuestra cultura. La idea de las fronteras poco nítidas del cuerpo humano se ha convertido en uno de los temas más repetidos y exitosos del género de la ciencia ficción, un tema especialmente atractivo en una época que algunos críticos han denominado "posthumana". Comenzando por las teorías de Norbert Wiener veremos diferentes aproximaciones a la idea del cyborg y de lo posthumano, lo que nos ayudará a comprender la cambiante relación entre máquina, robot y cyborg en Bicentennial Man (1999). Analizaremos de qué modo la película responde a la pregunta: qué significa ser humano en un mundo "posthumano"?

\footnotetext{
${ }^{1}$ This paper has been written with the financial help of the DGICYT, research project $\mathrm{n}^{\circ}$ BFF2001-1775.
} 
In 1976 Isaac Asimov wrote his long story “The Bicentennial Man”, about a standard housekeeping robot that wants to be human. In his search for humanity he will become first a cyborg and then a man, paying for it with his death. Both Isaac Asimov and Robert Silverberg wrote a longer version of the story that they called The Positronic Man, originally published in 1993. This was their third and last collaboration, Nightfall (1990) and The Ugly Little Boy (1992) being the other two, before Asimov's death on April 6th, 1992. This famous story has been adapted into a film called Bicentennial Man (1999) based on both the short story and the novel. In this paper, I will make reference to both the written story and the film adaptation but I will especially concentrate on the latter. In the short story and in the novel the narrative takes place in an undetermined future twenty-first century earth but in the film version we have "nearly" arrived at that future, as we recognise the Martin household as a typically wealthy white US suburban family. In addition, this last version is informed by the technological and scientific developments that have made its subject matter especially relevant. Thus, the film story concentrates on the robot's quest for identity in a world where many people have inadvertently become cyborgs. Taking this context into account, the film protagonist's evolution will be analysed in relation to the present theories about cybernetics and the posthuman in an attempt to understand the ways in which the film answers the question: where is the border between human and nonhuman in a "posthuman" world?

Bicentennial Man deals with a typical topic of science fiction. For Mark Rose all science fiction stories respond to a characteristic pattern. First there is a "estrangement" or "defamiliarisation", in which a familiar world is transformed into an unfamiliar one by means of a fantastic intruder (for example, an alien, a disease or a technological innovation). Secondly, there is a quest for an explanation of how the world transformation came about (1981: 26-7). In a sense, this could be the framework for the film. The story begins in a perfectly coherent world in the very near future. Richard Martin and his wealthy family acquire an NDR 114 domestic robot, which they nickname Andrew. However, they will soon discover that Andrew is not a normal robot, he has extraordinary artistic abilities, a taste for opera, and feelings. As a result, Andrew will initiate a quest to know the source of his uncannily human personality and in the process will try to find other robots sharing his abilities. In his search, we will become aware of the many traits that he shares with human beings. Precisely this human/nonhuman opposition is for Rose basic in science fiction. He analyses this blurred boundary through four fundamental categories: space (the nonhuman is projected out there), time (the nonhuman as a process that reveals itself in time), machine (humanity not only encounters the posthuman but is its creator) and monster (the nonhuman within humanity after the action of a transformation agency) (1981: 32-3). Science fiction works as mediator between the human and the nonhuman, creating a flexible field of tension that allows the blurring of semantic boundaries. In this sense, for Joseph D. Andriano the borderline that used to be feared was that between human and animal. Nowadays the new anxiety, the "angst" of postmodernity, concerns not only the beast but also the machine nearby; the modern robot makes way for the postmodern cyborg (1999: 155). This fearful blurred boundary between human and machine has stopped being a science fiction dream, since some scientists have started to see it as a very serious possibility. Ray Kurzweil 
(1999), a prestigious engineer and writer, has predicted that the $21^{\text {st }}$ century will see the blurring of the line between humanity and technology. By 2019 there will be computers capable of matching the processing power of the human brain. Ten years later the software for intelligence will have been mastered and a personal computer will be equivalent to 1,000 brains.

If we analyse the present moment, it is not far-fetched to state that many of these boundaries are already being eroded. Some science fiction dreams, such as directing brain to computer interfaces, are being seriously considered by scientists that firmly believe it can be done. Limb prosthetics is developing fast since nerves can be connected to silicon transducers. $^{2}$ As a consequence of these scientific breakthroughs, defining a monster or a machine has become increasingly difficult. In 1998 a team of surgeons was capable of implanting a corpse's hand into a patient's forearm, joining the bones of the patient's forearm to those of the donor's hand with nails, suturing the blood vessels and reestablishing the nervous connections and the tendons. Taking into account that Frankenstein, the fictional monster par excellence, was made out of the different limbs of a number of corpses, can we say that this man is a monster? In Atlanta in 1998, the American neurosurgeon Roy Bakay implanted two microelectrodes in the brain of some of his completely paralysed patients. These microelectrodes are able to register the impulses produced in the brain when the patient thinks of moving an object or a part of his/her body. A computer interprets the signals sent by the microelectrodes, allowing the paralysed patient to move the slide of the computer only with his/her mind. Are these men machines? Are they posthuman? Of course not, they are still men, but the meaning of being human has to be necessarily extended to include the last scientific advances.

Science fiction has always played an important role in the analysis and representation of the possible ethical implications of some future scientific advances. Some science fiction writers have even proved prophetic in their depiction of the future world. Already in the 1940s, Isaac Asimov himself started writing novels about robots and computers, in which he considered the problems and ethical implications of creating intelligent robots that could become hostile. Along the second half of the $20^{\text {th }}$ century robots have populated factories and computers have developed to a great extent. Even though Asimov's dream of thinking machines seems closer than we had thought, his real contribution was the posing of ethical questions about the nature of human beings. This is something that science fiction does, in fact for Scott McCracken cyborg fictions mediate the evolving relationship between humanity and technology, problematising the question of identity and exploring the transformations of what it means to be human (1998: 110-1). Representing new worlds involves a process of reflecting and comparing with society as it is now. For Istvan CsisseryRonay:

SF characteristically transforms scientific and technological ideas into metaphors, by which these ideas are given cultural relevance. It works very much like historical fiction in

\footnotetext{
${ }^{2}$ To read about some other scientific advances in this field see Vinge, 1993. Vinge is a scientist who, in line with Kurzweil, believes that in thirty years we will have the technological means to create superhuman intelligence, ending, thus, with the human era.
} 
this respect. It takes a body of extratextual propositions believed to be true, with no inherent ethical-cultural significance, and endows it with meaning by incorporating it in fictional stories about characters representing typical values of the author's culture. (In Parrinder, 1990: 69)

In this sense, in science fiction scientific ideas are taken to be transformed in ways relevant to the society of the time, becoming the perfect field to pose question such as what makes us different from machines? What should a machine do to be human? Before analysing in which ways the film tries to answer these questions, it is necessary to define three basic concepts that are key to the development of Andrew: the machine, the robot and the cyborg.

The story of the machine goes back to the 17th and 18th centuries, when the cosmos was viewed as a machine (the celestial clockwork) and the living bodies as automata. To compare the cosmos or even humanity to machines was to say that the world was explicable and could be controlled if its mechanism was found out. The Romantic Movement at the turn of the century was a reaction against this mechanistic worldview. As the process of industrialisation advanced, the general attitude in the 19th century shifted from delight in machines as the servants of man to fear of them as destroyers of life (Rose, 1981: 139-140). For John Ruskin, an influential Victorian critic of industrialisation, the idea of a manmachine became an almost ominous representation of evil:

Men were not intended to work with the accuracy of tools, to be precise and perfect in all their actions. If you will have that precision out of them, and make their fingers measure degrees like cog-wheels, and their arms strike curves like compasses, you must unhumanize them. All the energy of their spirits must be given to make cogs and compasses of themselves. (In Rose, 1981: 140-1)

With the Industrial Revolution the traditional lives of the European and American working classes were greatly disrupted. Work was detached from nature and instead of people known by a community, they became servants of the machine. Nonetheless, people ended up accepting machines, whose creation was in human hands (Poudrier, 1998: 292). This ambiguous representation of machines has always accompanied technological advances.

On the boundary between man and machine we find the robot, a magical figure prominent in science fiction precisely for its borderline position. Many have been the critics that have compared the robot to the human being. In 1950 dealing with the idea of the automata, the well-known mathematician Norbert Wiener wrote his famous book The Human Use of Human Beings: Cybernetics and Society. Since its date of publication the book has influenced the thinking not only of scientists and engineers but also of philosophers, sociologists and cultural critics. For him automata resembled men in their similar relationship to the environment. These life-imitating automata had to possess effector organs (like arms and legs) to perform tasks. They had to use sense organs (photoelectric cells and thermometers), which tell them the existing circumstances and 
enable them to record the performance or non-performance of their own tasks. Feedback is the name of this ability to adjust future conduct by last performance. Finally, they should have central decision organs that store the information, analogous to the memory of living organisms (Wiener, 1967a: 47-48). This ability to make decisions was for him basic, since it produced around the machine a local zone of organisation (negentropy) in a world whose general tendency is to run down, the same as happens with human beings. This conception of the automaton as a phenomenon partaking of the nature of living phenomena led him to wonder about how to define the term "life":

We are faced with the problem whether to enlarge the word "life" so as to include them (living phenomena), or to define it in a more restrictive way so as to exclude them ... Now that certain analogies of behaviour are being observed between the machine and the living organism, the problem as to whether the machine is alive or not is, for our purposes, semantic and we are at liberty to answer it one way or the other as best suits our convenience ... It is my opinion, therefore, best to avoid all question-begging epithets such as "life", "soul", "vitalism", and the like, and say merely in connection with machines that there is no reason why they may not resemble human beings in representing pockets of decreasing entropy in a framework in which the large entropy tends to increase. (Wiener, 1967a: 4647)

Wiener (1967a: 250) could not cope with his own theory's implications, so he preferred to ignore those terms that constituted a danger to his traditional ideology. When the boundary disruptions threatened to get out of hand he cautioned that humans must not let machines become their masters.

The subject of the boundary disruptions had already appeared in his previous and most well-known book, Cybernetics or Control and Communication in the Animal and the Machine (1948). Wiener is generally considered the father of cybernetics, a discipline that aims at studying the entire field of control and communication both in the machine and in the animal (1967b: 11). Cybernetics radically challenged the ways in which boundaries were conceived. For Katherine Hayles (1999: 84), Wiener's great success was his putting across the idea that the boundaries of the human subject are constructed rather than given. The idea that a cybernetic system is constituted by a flow of information brings forth very practical implications. One may think of the case of blind people that use a cane to walk and establish their position in relation to their surroundings. The cane is part of their bodies for this cane provides them with essential information about their environment, only together do they constitute a flow of information. Thus, taking into account these cybernetic theories, the boundaries of a human being can easily go beyond epidermal surface.

This kind of blurring of boundaries led to the serious consideration of the idea of the cyborg. The robot was a machine capable of imitating human beings; the cyborg was the actual combination of machine and human being in one, the actualisation of the mechanist metaphor of the human being as machine. The word "cyborg" was first used by Manfred E. Clynes and Nathan S. Kline in 1960 to describe "self-regulating man-machine systems" 
and in particular an "exogenously extended organizational complex functioning as an integrated homeostatic system unconsciously" (Tomas, 1995: 35). Clynes and Kline applied the concept to the problems of space travel. For Clynes the cyborg was more flexible than the human organism because it was not bound throughout a lifetime by heredity. Indeed, the cyborg was a reversible entity precisely because it was a "man-machine combination". In this way, the first scientific conceptions of the cyborg were directed towards practical aims, as an improvement upon the human body that might allow us to do things that a biological body could not do.

In contrast to the Clynes/Kline cyborg, which was conceived as a "superman" capable of surviving hostile non-earth environments, other concepts of the cyborg have emerged. Donna Haraway conceived the idea of the cyborg in her "A Cyborg Manifesto: Science, Technology, and Socialist-Feminism in the Late Twentieth Century" as a product of latecapitalist earth. A creature of social reality as well as a creature of fiction, the cyborg belongs to a post-gender world. In her opinion, this kind of high-technology challenges certain dualisms persistent in Western traditions. These dualisms have been deployed for the domination of those traditionally considered as "others". As Haraway puts it: "So my cyborg myth is about transgressed boundaries, potent fusions, and dangerous possibilities which progressive people might explore as one part of needed political work" (Haraway, 1991: 154). Thus, the cyborg becomes in Haraway's theory a transgression of hierarchical oppositions such as male/female, heterosexual/homosexual or Caucasian/other races among others.

David Tomas understands that both Clynes/Kline's and Haraway's cyborg deal with the modification and adaptation needed for the conquering and colonisation of non- or anti-human environments. For Haraway, such environments extend to the conflicting and hostile worlds of ideas and hierarchical oppositions (Tomas, 1995: 39). The cyborg's most recent transformations are computer-based. We are facing a new environment that consists of pure information: as a consequence, the best way to adapt human beings to this new environment is to transform the human organism into a pattern of pure digital information. Adaptation would be perfect and complete since organism and environment would be conceived in similar terms (1995: 39-40). Cyberpunk is the kind of science fiction that best adopts this set of ideas to the realm of literature, creating a complete human-machine fusion that allows the journey of the protagonist through the virtual world of pure data, where the flesh is left behind, overcoming the physical disabilities to allow the fluid flow of information. ${ }^{3}$

This brief story of the machine, the robot and the cyborg is basic to better understand Bicentennial Man. The first shots in the film, while the credits are still on, are close-ups of machines working in an assembly line in what looks like a perfectly autonomous system. We see them produce metal hands, heads and thousands of eyes for a company called "Robotics". These machines are not a threat to human beings because they are the economic equivalent of slave labour: they perform the kind of repetitive job that men detest to do.

\footnotetext{
${ }^{3}$ For a further account of cyberpunk in the context of general science fiction see McHale 1992, $225-242$. Cyberpunk in its relationship to postmodernism is further dealt with in McHale 1992, 243-267. For general ideas about the genre and an electronic interview with Bruce Sterling see Collado and Salvador 1998.
}

Odisea, $n^{\circ} 4,2003$ 
Later on we learn that they are producing housekeeping robots to be used for a similar kind of slavery, this time in direct contact with human beings. Everything is perfectly acceptable for the Martin family, who buy their NDR 113 as another of their commodities. NDR 113 will be named Andrew, this being the first step towards a long process of humanisation. The first thing Andrew does is display, in a virtual screen, the three laws of Robotics that he is bound to follow:

1. A robot may not injure a human being or, through inaction, allow a human being to come to harm.

2. A robot must obey the orders given by human beings except where such orders would conflict with the First Law.

3. A robot must protect its own existence as long as such protection does not conflict with the First or Second Law.

These laws protect human beings from a rebellion of robots and at the same time ensure the robot's slavery. They were created by Isaac Asimov and John Cambell (director of the magazine Astounding Science Fiction Stories) in 1941. The laws became very famous and were widely debated and discussed by science fiction writers that tried to spot failures and subvert them. At the beginning of the film Andrew blindly follows these laws, even when the wicked elder daughter of the Martins orders him to jump out of the window. After that episode it is agreed that since Andrew is a form of property, it will be treated with care.

This "adventure" leads to Andrew's progressive discovery of his uncanny human personality. When dusting he saves a spider and decides to fix an old gramophone that he will use at night to listen to opera. Later he will make a little horse out of a piece of wood for "Little Miss", the youngest and nicest daughter of the Martins. Richard Martin is proud of Andrew's creativity, curiosity and fellowship. This admiration is not shared by the director of Robotics that, unlike the machines that created Andrew, sees in him a threat and tries to buy it back so as to destroy it. Of course, Mr Martin refuses the proposal since Andrew's uniqueness has no price for him. At this point we may wonder which are the film's premises to make the difference between a robot's personality and a human being's. In a sense, the film shares some of the values defended by Norbert Wiener. For Katherine N. Hayles, Wiener was deeply informed by the values of liberal humanism, the values that define a human being. These are "a coherent, rational self, the right of that self to autonomy and freedom, and a sense of agency linked with a belief in enlightened self-interest" (1999: 85-86). For Wiener the cybernetic machine, the robot being its equivalent in the film, had to be designed so that it did not threaten the autonomous, self-regulating subject of liberal humanism. Though this was Wiener's belief, his theory of cybernetics turned out to be too daring to be compatible with his liberal humanism.

In the film Richard Martin's position is very similar to that of Norbert Wiener in his theories. He is willing to teach Andrew how to tell jokes or how children are conceived, but he is not willing to apply the liberal humanism precepts to Andrew. Little Miss' attitude is completely different. She convinces her father that Andrew should have a bank account of 
his own, so that he can save the money he earns by making clocks. In Asimov's original version Andrew worked as a carpenter, which misses some of the implications of having a machine (a robot) produce other machines (clocks). Kurzweil (1999) has pointed out that one of the greatest fears in the developing of machines is that humans may create intelligent machines that might create their own next generation without human intervention. A generation of machines which would exceed the intelligence of its creators and which would pose a serious threat to human beings. In the film this is a non-threatening perfect system that will be broken when Andrew initiates his quest to become a human being. The story of how we achieve our humanity is one of the greatest stories of modern Western culture. There are mythical tales such as Pinocchio where an inanimate being acquires a life and a personality of its own. Another example is the old Jewish myth of the Golem, a being created from clay to protect the Jews, and who also wanted to become a person turning even against its creator. Frankenstein's story is deeply indebted to these early myths and so are the many science fiction films that have toyed with this idea, such as Ridley Scott's Blade Runner (1982) or the Star Trek series. In Bicentennial Man, when Andrew decides that he wants to be free and initiates his quest for humanity, Little Miss is the first to back and support him. Richard reluctantly grants him his freedom but refuses to see him again. As Hayles explains "if owning oneself was a constitutive premise for liberal humanism, the cyborg complicated that premise by its figuring of a rational subject who is always already constituted by the forces of capitalist markets" (1999: 86-87). From the moment in which Andrew owns himself he acquires a basic human-being right, which brings about Richard's negative reaction.

After gaining his freedom, Andrew's next step in his search for identity will be his becoming a cyborg (a man-machine). After Little Miss' marriage and Richard's death he initiates a quest for self-consciousness. He looks for other robots like himself but all of them have been deleted. He goes west looking for freedom, the same route the first American pioneers followed in their own search for the American dream. His journey finishes in San Francisco where he meets Rupert Burns, the son of the man that created him. Rupert lives with Galatea, a female robot that has no more personality than the one provided by a personality chip. The comparison of Galatea, Andrew and Rupert shows how Andrew has come to disrupt the hierarchical man/robot opposition, making Rupert aware of the unfairness of treating Galatea as a slave. With Rupert's help, Andrew becomes an android, making his external appearance completely human. His internal organs are still mechanical rather than biological but at least in appearance he looks like a man. He finally returns to Little Miss and after her death he falls in love with Portia, Little Miss' granddaughter. Portia will help him to complete his psychological transformation.

For Philip K. Dick, author of Do Androids Dream of Electric Sheep? (renamed Blade Runner in its film adaptation), the characteristics that set the human apart from the android are its being unique, acting unpredictably, experiencing emotions, feeling vital and alive. Of course this is a list of qualities that the liberal humanist subject is supposed to have. Yet, every item on the list is brought into question by the humans and androids of Dick's fiction. Something similar happens in Bicentennial Man. Portia encourages Andrew to lie, to feel love, to feel jealous and to make mistakes. If the Victorian critic of industrialisation 
John Ruskin was against men becoming perfect machines in the industrial system, Andrew (a robot in a capitalist system) has to become imperfect and make mistakes so as to become a human being. This psychological transformation is accompanied by a physical one; he obtains a new nervous system that permits him to experience sensations and makes him physically fit to have sex. Portia, who was about to marry another man, breaks the engagement and both confess their feelings for each other. The very last fusion is achieved when both have sexual intercourse. Some critics, such as Mike Higgins have found this relationship difficult to accept. As he points out:

Indeed, the one distinguishing feature in this narrative desert -Little Miss' unrequited love for Andrew and his eventual marriage to her granddaughter- leaves a nasty taste in the mouth precisely because we are asked to consider as straightforwardly romantic a cross-generational, quasi-incestuous relationship between a 150 -year-old robot and a young woman. It makes you imagine what Bicentennial Man could have been like in the hands of David Cronenberg. (Higgins, 2000: 42)

Cronenberg has already dealt with such kind of fusions and the results have not been romantic comedies but horror stories. As an example it comes to mind the ending of The Fly (1986). Seth Brundle, by now a monstrous fusion of fly and man, wants to transport himself and Ronnie (pregnant of him) in the telepod to fuse their three into one. The final result is that his monstrous body fuses with the telepod, the machine itself, becoming a fly/ man/machine monster that can only beg for death. ${ }^{4}$

Bicentennial Man may be a science fiction drama, a family saga or a children's comedy but certainly it is not a horror film. This is not just Frankenstein's myth revisited, in fact, one of the basic objectives of Isaac Asimov was to counteract the stereotype of the robot that the genre has presented so far. He named this stereotype "the Frankenstein's complex", since the creators of robots always ended up being killed by their own creations. He might agree to a confrontation between creator and creature but for him there was no need of destruction (Cornell, 1994: XIV). Asimov's rejection of "the Frankenstein's complex" was present in his original long story "The Bicentennial Man", and is certainly maintained in this film adaptation. However, in the long story, Andrew's integration did not go as far as to have sexual intercourse with a woman. In Asimov's original version Andrew was too busy writing a book on robotics, becoming a "robobiologist", creating a new science called "prosthetology" and manufacturing prosthetic devices both for him and for human beings. The kind of transformation that Andrew undergoes in the book is physical but nearly nothing is said about the psychological implications of being human. In the film Portia is responsible for that transformation, whose climax is their sexual intercourse. In my opinion this last "fusion" works well in the film since it represents the final step in his becoming a normal human being, in his attempt to integrate in a society that rejects what is "other", and being a positronic robot is certainly being "other".

The figure of the sentient machine, which represents not only pure consciousness but self-consciousness (Poudrier, 1998: 292), is a figure whose role has evolved with the

\footnotetext{
${ }^{4}$ For a further analysis of the implications in The Fly of such fusions see Jennifer Wicke 1996.
} 
passing of time. It started being a threat to humans, the antagonist of the seeker, who had to face the monster so as to complete his quest. The two weaknesses of these machines are their adherence to logic and their lack of individualisation: they have no imagination and this prevented them from reacting in unexpected situations. The case of the human-machine is more ambiguous. On many occasions the human side loses its capacity to react as a human and his free will. Some other times the human part gains power, which marks the progressive acceptance of the necessity of machines, as Poudrier points out the machine "can no longer just be conquered, junked, and forgotten" (296). This leads us to the many narratives where the sentient machine takes the role of the seeker and becomes the hero of the story, starting a journey into self-knowledge which mirrors our own concerns. This is the case of the replicants in Blade Runner (1982), or Data, the android Lieutenant Commander of the Enterprise in Star Trek: The Next Generation (1991). A more recent example is the robot child, David, in Steven Spielberg's A.I. Artificial Intelligence (2001). David wants to become a real child in order to recover the love of her human step-mother, who has abandoned him after the recovery of her real human son. It is in this context that we can place Andrew in Bicentennial Man, as a man/machine that turns seeker/hero of the story and with whom the audience identifies.

Nevertheless, can we say that boundaries are completely eroded in the final part of the film? Could we consider Andrew's quest for humanity a success? After Andrew's sexual intercourse with Portia he decides that he wants to be declared a human being but the World Congress states that Andrew's immortality prevents the Congress from recognising him as a human being, also rejecting his marriage attempt. His defence is very interesting: while transforming himself into a human, Andrew has also created a set of prosthetic organs, such as kidneys, eyes and hearts that can be used by human beings. When the trial takes place Andrew reminds the jury that many of them have those devices inside. These people are artificial to a certain extent, in the same way he is partly human. His argument is that if we accept that no number of artificial artefacts in the human body causes it to cease being a human body, we should also accept a broad interpretation of humanity that might include Andrew. Wiener's theories are behind this argument. He created a theory of communication wide enough to include the animal and the machine; Andrew proposes a theory of humanity wide enough to include him. Of course, this is something that Wiener would have never accepted since his liberal humanist theory was to be applied only to human beings. In the long story there is an interesting passage where the congresswoman Chee LI-Hsing summarises to Andrew the negative implications of creating prosthetic devices and broadening the interpretation of humanity. She states that "it will be said it was part of a campaign to robotize human beings, or to humanize robots; and in either case evil and vicious" (Asimov, 1976: 201). Since 1976 the way we understand humanity has certainly evolved. As Hayles summarises nowadays:

Cyborgs actually exist. About 10 percent of the current U.S. population are estimated to be cyborgs in the technical sense, including people with electronic pacemakers, artificial joints, drug-implant systems, implanted corneal lenses, and artificial skin. A much higher percentage participates in occupations that make them into metaphoric cyborgs, 
including the computer keyboarder joined in a cybernetic circuit with the screen, the neurosurgeon guided by fiber-optic microscopy during an operation, and the adolescent game player in the local video-game arcade. (1999: 115)

These progressive evolution in the concept of humanity may lead us to believe that we are entering the posthuman. In 1977 Ihab Hassan coined for the first time the term "posthuman" referring to how the human form, including human desire and its external representations, was changing radically. Hayles tries to analyse what we understand by "the post-human", which is characterised by a series of assumptions. First, it privileges the informational pattern over materiality and understands our embodiment as merely accidental. Second, consciousness (the seat of human identity) becomes a minor sideshow. Third, the body turns into the original prosthesis we all learn to manipulate and fourth there are no absolute demarcations "between bodily existence and computer simulation, cybernetic mechanism and biological organism, robot teleology and human goals" (1999: 3). The February 2000 issue of Wired magazine featured a cover story by Kevin Warwick called "Cyborg 1.0: Kevin Warwick Outlines His Plans to Become One with His Computer". This man has been installing in his body implants which have miniature transmitters that link various signals from his nervous system and other bodily activities with his computer. This is Hayles' idea of the posthuman made true: the body as the original prosthesis we learn to manipulate. The idea of the posthuman provokes terror since it connotes the end of humanity as we know it; however, it can also evoke pleasure since the loss of liberal humanism is not something affecting all human beings. We have to take into account that liberal humanism is a conception that has only applied to a fraction of humanity who "had the wealth, power, and leisure to conceptualize themselves as autonomous beings exercising their will through individual agency and choice" (Hayles, 1999: 286). The post-human is not the anti-human, it is rather a collaboration between human and nonhuman agents in order to achieve the survival of humans and other life-forms in new changing environments. The capacity to change is what makes humans survive.

In Bicentennial Man, seventy-five years after the first trial, Andrew is finally granted his humanity. To do so, Andrew has to make a final sacrifice: he must die. As he puts it, he prefers to die as a man rather than live the whole eternity as a robot. This ending is surprisingly conservative. Society in the film is willing to accept the fusion with the other only when the other has disappeared. The social order is constituted by different positions in a classificatory system and meaning is imposed in the world through binary oppositions. For Mary Douglas, what really disturbs this order are those things placed in the wrong category or things that do not fit in any category. What we do with these things is to expel them, in this way restoring the social order (Douglas, 2001). By the end of the film, Andrew is not completely a machine, a robot, a cyborg or a human being. He has become matter out of place. Mike Higgins' comments about the film, already quoted above, become especially relevant now. The relationship between Portia and Andrew leaves him a "nasty taste" because he cannot accept the union between a woman and something that does not fall under a clear category. In an attempt to classify Andrew, Higgins calls him a 150-year-old robot, but at this point Andrew is anything but a robot. The film's only escape to turn the 
plot into a family comedy and not into a Cronenberg-like horror story, is to make the lovers die (of old age, of course). The spectators feel satisfied because the film provides them with positions that are progressive enough to accept Andrew as human being, at the same time feeling secure in their ordered world where human/non-human categories still apply. This is consistent with Hayles' dream-like version of the posthuman that embraces: "the possibilities of information technologies without being seduced by fantasies of unlimited power and disembodied immortality, that recognizes and celebrates finitude as a condition of human being, and that understands human life is embedded in a material world of great complexity, one on which we depend for our continued survival" (1999: 5). Wiener put the limit of humanity in the fulfilment of liberal humanism, Hayles puts it in the idea of mortality. Immortal otherness is still difficult to accept.

Bicentennial Man is a film that, in spite of being in essence the old bourgeois narrative of social improvement (body improvement in this case), makes us feel that we are witnessing a "posthuman" future of blurred boundaries and overcoming of differences. However, this new concept of the human being and the machine is still very far away from Haraway's dreams of the cyborg as a creature of social reality as well as a creature of fiction in a postgender world. For Haraway:

Unlike the hopes of Frankenstein's monster, the cyborg does not expect his father to save it through a restoration of the garden; that is, through the fabrication of a heterosexual mate, through its completion in a finished whole, a city and cosmos. The cyborg does not dream of community on the model of the organic family, this time without the oedipal project. The cyborg would not recognize the Garden of Eden; it is not made of mud and cannot dream of returning to dust. (1991: 151)

Andrew does ask his father, or rather the son of his father, to restore for him the Garden of Eden. He wants to become not only a human being but also a man. He does look for a heterosexual mate, Portia, and does dream of an organic family, feeling terribly deceived when he is not allowed to marry Portia in a church as is proper. Andrew is not made of mud but he certainly dreams of dying as the only means to be accepted by that community that for Haraway the cyborg should reject. By the end of the film the spectator is willing to accept Andrew, but taking into account Andrew's conservative dreams and goals this is not especially daring. And even so we still make him pay a high price, the highest price: death. A boundary we have not learned how to erase yet.

\section{BIBLIOGRAPHY}

Asimov, I. 1976. The Bicentennial Man. London: Grafton Books.

Asimov, I and R. Silverberg. 1995 (1993). The Positronic Man. Bantam Spectra.

ANDriano, J. D. 1999. Immortal Monster: The Mythological Evolution of the Fantastic Beast in Modern Fiction and Film. Westport: Greenwood Press. 
Collado Rodríguez, F. and S. Salvador Sebastián. 1998. "Post-human: The Cultural Limits of 'Cyberpunk' (Including an Electronic Conversation with Bruce Sterling, and his own Selected List of Cyberpunk Readings)". Miscelánea: A Journal of English and American Studies 19: 21-37.

CoRnell, P. 1994. Introducción a Robbie y otros Relatos. Barcelona: Vicens Vives. VI-XXIV.

Douglas, M. 2001 (1966). Purity and Danger: An Analysis of Concepts of Pollution and Taboo. London and New York: Routledge.

Haraway, D. J. 1991. "A Cyborg Manifesto: Science, Technology, and SocialistFeminism in the Late Twentieth Century". Simians, Cyborgs, and Women: The Reinvention of Nature. London: Free Association Books. 149-181.

Hayles, K. N. 1999. How We Became Posthuman: Virtual Bodies in Cybernetics, Literature, and Informatics. Chicago: The University of Chicago Press.

Higgins, M. 2000. "Film Review of Bicentennial Man”. Sight and Sound 10, 3: 4142.

KurzweIL, R. 1999. The Age of Spiritual Machines. New York: Viking Penguin.

. 1999. "The Coming Merging of Mind and Machine". Scientific American. September 19. <http://www.sciam.com/article.cfm?articleID=0007EE6E-F71F1C72-9B81809EC588EF2>

McCracken, S. 1998. Pulp: Reading Popular Fiction. Manchester and New York: Manchester University Press.

McHale, B. 1992. Constructing Postmodernism. London and New York: Routledge.

PARRINDER, P. 1990. "Scientists in Science Fiction: Enlightenment and After". Science Fiction Roots and Branches: Contemporary Critical Approaches. Eds. R. Garnett and R. J. Ellis. London: Macmillan. 57-78

Poudrier, A. F. 1998. "Its Continuing Mission: Star Trek's Machine Mythology and the Quest for Self'. The Soul of Popular Culture: Looking at Contemporary Heroes, Myths and Monsters. Ed. Mary Lynn KitTELson. Chicago and La Salle: Open Court. 290-303.

Rose, M. 1981. Alien Encounters: Anatomy of Science Fiction. Cambridge: Harvard University Press.

Tomas, D. 1995. "Feedback and Cybernetics: Reimaging the Body in the Age of the Cyborg" Cyberspace, Cyberbodies, Cyberpunk: Cultures of Technological Embodiment. Eds. M. Featherstone and R. Burrows. London: Sage. 21-43.

VINGE, V. 1993. "The Coming Technological Singularity: How to survive in the PostHuman Era". Whole Earth Review, 81, Winter. $<$ http://www-rohan.sdsu.edu/faculty/ vinge/ misc/singularity.html > 
Warwick, K. 2000. “Cyborg 1.0: Kevin Warwick Outlines His Plans to Become One with His Computer". Wired, 8.02, February. <http://www.wired.com/wired/archive/8.02/ wawick.html>

Wicke, J. 1996. "Fin de Siècle and the Technological Sublime". Centuries' Ends, Narrative Means. Ed. R. Newman. Stanford: Stanford University Press. 302-315.

WienEr, N. 1967a (1948). Cybernetics or Control and Communication in the Animal and the Machine. Cambridge: The M.I.T. Press.

1967b (1950, 1954). The Human Use of Human Beings: Cybernetics and Society. New York: Avon Books. 